\title{
Morfologia e funcionalidade do pneumócito tipo II e sua relação e variação com a idade gestacional em bovinos
}

\author{
Morphology and functionality of the type II pneumocytes and their variation in relation to bovine \\ gestational age
}

\author{
Rita de Cássia Toquetti ${ }^{1}$ Ricardo Romão Guerra ${ }^{\mathrm{I}}$ Carlos Eduardo Ambrosio ${ }^{\mathrm{I}, \mathrm{II}^{*}}$ \\ José Manoel Santos ${ }^{\mathrm{I}}$ III Phelipe Oliveira Favaron ${ }^{\mathrm{I}}$ André Luiz Rezende Franciolli ${ }^{\mathrm{I}}$ \\ Miryan Vilia Alberto ${ }^{\mathrm{I}}$ Flávio Vieira Meirelles ${ }^{\mathrm{I}, \mathrm{II}}$ Maria Angelica Miglino ${ }^{\mathrm{I}}$
}

\section{RESUMO}

Este estudo objetivou caracterizar a presença de pneumócitos tipo II e o início da produção de lipoproteína surfactante em bovinos, correlacionando a idade gestacional com a síntese de surfactante durante o desenvolvimento fetal. Pulmões de fetos com quatro meses de idade gestacional estavam na fase canalicular de desenvolvimento, sem a presença de pneumócitos tipo II ou bandas eletroforéticas compatíveis com a presença de proteínas surfactante. No 5 o mês gestacional, os pulmões dos fetos encontravam-se em fase de saculação terminal, com a presença de alvéolos por epitélio cúbico, com áreas formadas por pneumócitos I e II. Nesse período ainda não foi possível identificar proteína surfactante nos pulmões. Esses órgãos em fetos com seis meses de idade gestacional estavam em fase de saco terminal, com presença de pneumócitos tipo I e II. Nessa fase a análise para determinação protéica do surfactante de feto bovino (SDS - PAGE) demonstrou presença de bandas entre 26 e 36kDa, confirmando produção de SP - A, proteína surfactante encontrada em maior quantidade. A partir do $7^{\circ}$ mês gestacional, a fase de saco terminal é mais evidente e complexa, com desenvolvimento de intensa vascularização. O pneumócito tipo I apresentava aspecto mais pavimentoso, e o tipo II apresentava aspecto mais globoso. Na análise SDS - PAGE do lavado bronco alveolar, bandas de proteína surfactante com aspecto similar ao de animais recém-nascidos foram encontradas. Em recémnascidos, pulmões na fase alveolar foram observados com pneumócitos tipo I e II característicos. O perfil das bandas do lavado bronco-alveolar dos recém-nascidos foi igual ao de animais adultos. Esses achados sugerem que um animal nascido precocemente, a partir dos sete meses de gestação, teria sua sobrevivência garantida devido a uma possível funcionalidade do sistema respiratório do feto, pois o pulmão possuiria as características necessárias para a síntese de proteínas surfactantes. Entretanto, mais estudos clínicos sobre a funcionalidade do sistema respiratório abrem novas fronteiras de experimentos sobre fisiologia respiratória em recém-nascidos bovinos.

Palavras-chave: pneumócito tipo II, pulmão, proteína surfactante, bovino.

\section{ABSTRACT}

The aim of this study was to characterize the presence of type II pneumocyte and the beginning of the surfactant protein production in bovines to the correlated gestational age. Lungs of fetuses at 4 months gestational age were found to be in the canalicular development phase, without presence of type II pneumocytes or appearance of electrophoretic bands compatible with the presence of the surfactant protein. In fetuses at 5 months of gestational age, the lungs were at the terminal sac phase, with the presence of primitive alveolus, formed by cubical epithelium and areas formed by pneumocytes $I$ and pneumocytes II. No electrophoretic bands compatible to the surfactants proteins were identified. In contrast, lungs of fetuses at 6 months of gestational age showed, development of terminal sac phase, with the presence of type I and type II pneumocytes. In this phase, proteic determination for the SDS - PAGE analysis showed the presence of bands between 26 to $36 \mathrm{kDa}$, demonstrating SP - A production, which is the surfactant protein found in highest amount. From the 7 th gestational month on, the phase of terminal sac is more evident and complex, with intense sprouting vascularization. The type I pneumocyte had a more squamous aspect and type II pneumocyte were more globular. In the SDS - PAGE analysis of the bronchial - alveolar wash, surfactant protein bands had been observed with a profile similar to that of the newborn animals. In newborn animals, lungs in alveolar phase showed the development of type I and II pneumocytes. The profile of

'Programa de Pós-graduação em Anatomia dos Animais Domésticos e Silvestres, Departamento de Cirurgia, Faculdade de Medicina Veterinária e Zootecnia (FMVZ), Universidade de São Paulo (USP), São Paulo, SP, Brasil.

${ }^{I}$ Departamento de Ciências Básicas, Faculdade de Zootecnia e Engenharia de Alimentos (FZEA), USP. Av. Duque de Caxias, 225, 13635-900, Pirassununga, SP, Brasil. E-mail:ceambrosio@usp.br.*Autor para correspondência.

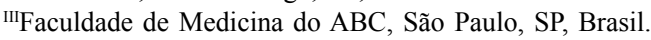


the bronchial - alveolar wash from the newborn was similar to an adult animal, presenting the same bands in triplets. These results suggest that early born fetuses, from 7 months of pregnancy could have a guarantee of surviving due to possible functionality of respiratory system because the lung presented all necessary features for surphactant protein syntheses. However, new clinical studies related to respiratory system functionality open new venues for newborn bovine's experiments respiratory physiology.

Key words: type II pneumocyte, lung, surfactant protein, bovine.

\section{INTRODUÇÃO}

O desenvolvimento dos pulmões engloba três fases denominadas de acordo com as características microscópicas dominantes: a primeira fase (glandular) determina o padrão brônquico, a segunda fase (canalicular) estabelece a porção respiratória do pulmão, a terceira e última (alveolar) diz respeito ao desenvolvimento dos alvéolos (DYCE, et al., 2004). O pulmão tem origem de um broto epitelial do endoderma do intestino primitivo, sendo os túbulos epiteliais circundados por células mesodérmicas (BURRI, 1984; PETERS et al., 1994; CARDOSO, 1995, RIBEIRO et al., 1998).

O período gestacional em bovinos taurinos é de 280 dias (NODEN \& LAHUNTA, 1990). Por volta do $45^{\circ}$ dia de gestação, inicia-se o período fetal, que se estende até o nascimento e que se caracteriza pelo rápido crescimento, pela maturação fisiológica dos órgãos e pelas modificações morfológicas no concepto (HAFEZ \& HAFEZ, 2004).

Para a sobrevivência do feto ao nascer, é necessário, dentre outros fatores, que haja um perfeito desenvolvimento e amadurecimento do sistema respiratório, envolvendo a transformação dos pulmões de órgãos secretores em órgãos de trocas gasosas, e que haja a produção de surfactante, uma lipoproteína sintetizada e secretada por células alveolares específicas; os pneumócitos tipo II (JUNQUEIRA \& CARNEIRO, 2004; MOORE \& PERSAUD, 2004; O'RAHILLY \& MULLER, 2005).

O surfactante pulmonar tem por função reduzir a tensão superficial na interface ar - líquido dos alvéolos (GOERKE \& CLEMENTS, 1986), estabilizando-os quando o pulmão está com seu volume reduzido. Essa propriedade reduz o trabalho respiratório e previne a transudação dos fluídos para o espaço alveolar (MOORE \& PERSAUD, 2004; O’RAHILLY \& MULLER, 2005). Na literatura não há referências sobre a cronologia do aparecimento do surfactante em bovinos, o que despertou o interesse dos autores por esse assunto. Além disso, pesquisas atuais de nosso grupo investigam a presença dessas proteínas em fetos bovinos clonados. Portanto, o presente trabalho almejou estabelecer parâmetros morfofisiológicos durante o desenvolvimento fetal para confrontar com material oriundo de clones bovinos, pois esses animais nascem com grande débito respiratório e uma hipótese disso seria a falta de produção de surfactante nos pulmões de bovinos clonados, por transferência nuclear, origem esta da problemática das trocas gasosas devido a fatores epigenéticos relacionados a embriologia do sistema respiratório e manipulação in vitro dos embriões. Dessa forma, este trabalho visou a estudar o pulmão em fetos bovinos, enfatizando a morfologia e a funcionalidade dos pneumócitos do tipo II e correlacionando a idade gestacional com a síntese de surfactante durante o desenvolvimento fetal.

\section{MATERIAL E MÉTODOS}

Coleta de material e análise macroscópica

Foram utilizados 30 fetos bovinos das raças

Bos taurus e Bos indicus e/ou cruzados, em diferentes estágios de desenvolvimento, oriundos de frigoríficos da região de São José dos Campos, São Paulo. Para a determinação da idade gestacional, os fetos foram submetidos à metodologia preconizada por EVANS \& SACK (1973), NODEN \& LAHUNTA (1990) e ASSIS NETO et al. (2009). O Crown Rump-CR foi mensurado com o auxílio de fita métrica. Além disso, estes foram pesados em uma balança (Marte Balança e aparelhos de Precisão Ltda, Modelo AL500, São Paulo - SP). Para referência morfológica e protéica, foram utilizados dois animais recém-nascidos que vieram a óbito (ambos com sistema respiratório integro) logo após o nascimento e um animal adulto (Tabela 1).

Processamento para avaliação em microscopia de luz O material foi fixado em Bouin por 12 horas, seguido de desidratação em álcool etílico, em concentrações crescentes, diafanização em xilol e posterior inclusão em paraplast. Foram obtidos cortes de $5 \mu \mathrm{m}$ em micrótomo (Leica RM2155, Germany), os quais foram corados por hematoxilina e eosina.

Processamento por microscopia eletrônica de transmissão

Fragmentos do pulmão foram fixados em glutaraldeído 2,5\%, em tampão fosfato $0,1 \mathrm{M}, \mathrm{pH} 7,2$, e posteriormente lavados em tampão fosfato a $0,1 \mathrm{M}, \mathrm{pH}$ $7,43 \mathrm{x}$, sendo pós-fixados em tetróxido de ósmio $1 \%$ por uma hora. O material foi desidratado em 
Tabela 1 - Tamanho dos fetos bovinos (Bos indicus e Bos taurus) coletados e período gestacional estimado conforme as medidas de Crown - Rump e seus respectivos pesos.

\begin{tabular}{|c|c|c|c|}
\hline Amostra & Tamanho do feto $(\mathrm{cm})$ & Dias de gestação & Peso $(\mathrm{kg})$ \\
\hline 1 & 24,5 & 125 & 1,2 \\
\hline 2 & 26 & 126 & 1,8 \\
\hline 3 & 29 & 136 & 1,2 \\
\hline 4 & 30 & 138 & 1,64 \\
\hline 5 & 30 & 138 & 1,94 \\
\hline 6 & 32 & 142 & 2,01 \\
\hline 7 & 35 & 148 & 3 \\
\hline 8 & 43 & 166 & 4,12 \\
\hline 9 & 44 & 170 & 4,5 \\
\hline 10 & 44,5 & 170 & 4,99 \\
\hline 11 & 45 & 173 & 4,5 \\
\hline 12 & 45,5 & 173 & 4,9 \\
\hline 13 & 46 & 175 & 5 \\
\hline 14 & 58 & 198 & 9 \\
\hline 15 & 59 & 200 & 9,35 \\
\hline 16 & 60 & 205 & 9 \\
\hline 17 & 62 & 210 & 12 \\
\hline 18 & 67 & 220 & 13 \\
\hline 19 & 68 & 220 & 16,35 \\
\hline 20 & 69 & 220 & 11,15 \\
\hline 21 & 69 & 220 & 18 \\
\hline 22 & 69 & 220 & 15 \\
\hline 23 & 72 & 233 & 15 \\
\hline 24 & 75 & 235 & 16,44 \\
\hline 25 & 78 & 235 & 16,50 \\
\hline 26 & 79 & 235 & 23 \\
\hline 27 & 79 & 235 & 23 \\
\hline 28 & 84 & 246 & 21 \\
\hline 29 & 87 & 250 & 29 \\
\hline
\end{tabular}

concentrações crescentes de álcool e lavado em óxido de proprileno. Os fragmentos permaneceram sob rotação a 1:1 de óxido de propileno e resina por $14 \mathrm{~h}$. Essa mistura foi substituída por resina pura por quatro horas nos moldes. Os blocos foram cortados usandose um ultramicrótomo (Ultracut R, Leica Microsystems, Germany). Os cortes ultrafinos $(60 \mathrm{~nm})$ foram contrastados pelo acetato de uranila $2 \%$ em água destilada, por cinco minutos, e pelo citrato de chumbo $0,5 \%$ em água destilada, por 10 minutos, e posteriormente analisados ao microscópio eletrônico de transmissão (Morgani 268D, FEI Company, Soft Imaging System, Germany).

Coleta protéica do surfactante de feto bovino

Foi realizada uma incisão na traquéia, na qual se introduziu um cateter e, por meio deste, solução fisiológica de Cloreto de Sódio a 0,9\% (KOGISHI et al., 1988). Em seguida, realizou-se massagem torácica para se obter o lavado pulmonar. O lavado foi centrifugado a $4.000 \mathrm{rpm}$ por $30 \mathrm{~min}$, à temperatura de $4^{\circ} \mathrm{C}$. Após essa primeira centrifugação, o sobrenadante foi retirado, e realizou-se uma nova centrifugação a $30.000 \mathrm{rpm}$ por $120 \mathrm{~min}$, à temperatura de $4^{\circ} \mathrm{C}$. O material obtido após a ultracentrifugação foi utilizado para a análise protéica.

Quantificação de Proteína total e SDS-PAGE

Para a determinação protéica total, foi utilizado o kit reagente para ensaio de proteína (Instructions BCA Protein Assay Reagent Kit). Esse método utiliza ácido bicinchonínico para detecção colorimétrica e quantificação total de proteína.

Para a eletroforese, foram utilizados $26 \mu \mathrm{g}$ de proteína diluída em tampão contendo $\beta-$ mercaptoetanol, glicerol, SDS, azul de bromofenol e solução tampão Tris $-\mathrm{HCl}$ 0,0625M. A corrida foi feita à temperatura ambiente, $30 \mathrm{~mA}$, por aproximadamente duas horas em gel com $12,5 \%$ de poliacrilamida. Foi utilizado marcador de peso molecular, com massas moleculares de 94, 67, 45, 30, 20 e 14kDa. O gel foi corado pelo método de coloração de prata (BLUM et al., 1987).

\section{RESULTADOS E DISCUSSÃO}

Objetivando obter referências morfológicas e bioquímicas do início da síntese de surfactante pelos pulmões, o estudo iniciou com fetos em idade gestacional de quatro meses (a partir dos 120 dias), visto que, em idade inferior a essa, não há estruturas pulmonares relacionadas com a síntese de surfactante. Para tanto, os fetos foram mensurados, sendo estimado o Crown-rump de cada um (Tabela 1), seguindo-se a referência de EVANS \& SACK (1973).

Os fetos com idade gestacional de quatro meses apresentaram pulmões na fase canalicular, na qual os brônquios e os bronquíolos apresentaram lúmen amplo. Os bronquíolos apresentaram-se formados por epitélio colunar baixo, núcleo no pólo apical da célula, e sem cílios. Junto ao tecido conjuntivo (TC), foi possível observar, nos bronquíolos maiores, a presença de uma camada de tecido muscular liso e de capilares sanguíneos (Figuras 1A e 1B).

Estes achados diferem dos descritos por MOORE \& PERSAUD (2004), SADLER (2005) e O'RAHILLY \& MULLER (2005), que fazem alusão principalmente ao desenvolvimento embrionário em humano. Foi observado que em bovinos a fase canalicular mostra-se com características primárias quando comparadas ao período pseudoglandular e com ausência de células ciliadas, característica que, segundo as referências, deveriam estar presentes 


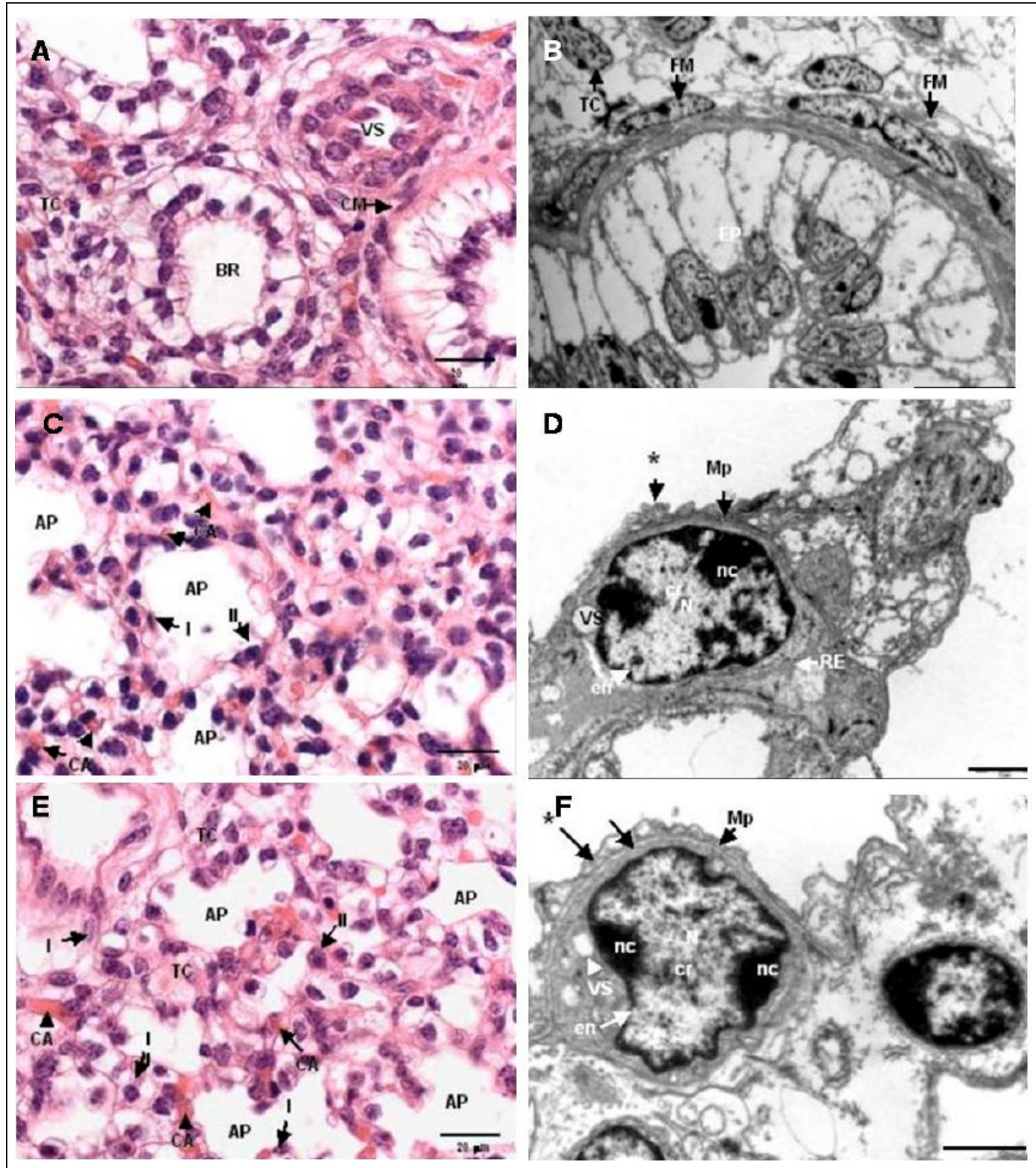

Figura 1 - Pulmão de fetos bovinos (Bos indicus e Bos taurus) em diferentes estágios de desenvolvimento. Em A e B: Corte histológico e eletromicrografia de pulmão aos quatro meses de desenvolvimento respectivamente, fase canalicular. Notar as estruturas: bronquíolo respiratório (BR), camada muscular (CM), vaso sanguíneo (VS), septo conjuntivo (SC), tecido conjuntivo (TC), epitélio do bronquíolo respiratório (EP), fibras musculares lisas da camada muscular (FM). Em C e D: Fase canalicular no $5^{\circ}$ mês de desenvolvimento. Em C: notar na microscopia de luz: alvéolo primitivo (AP), pneumócito tipo I (I), pneumócito tipo II (II), capilar alveolar (CP) e tecido conjuntivo (TC). Em D: eletromicrografia evidenciando a parede de um alvéolo primitivo em fase de saco terminal no $5^{\circ}$ mês do desenvolvimento. Notar: pneumócito tipo II contendo vesículas (VS), membrana plasmática (Mp), retículo endoplasmático (RE), núcleo (N) contendo cromatina (cr), envoltório nuclear (en), nucléolo (nc). Presença de parte do citoplasma do pneumócito tipo I (*). Em E e F: Pulmão em fase de saco terminal, no $6^{\circ}$ mês de desenvolvimento. Notar: alvéolo primitivo (AP) contendo pneumócito tipo I (I) e pneumócito tipo II (II), capilar alveolar (CA) e tecido conjuntivo (TC). Em F: eletromicrografia mostrando parede de um alvéolo primitivo. Pneumócito tipo II com vesículas no seu interior (VS), membrana plasmática (Mp), núcleo (N) com cromatina (cr) e envoltório nuclear (en), nucléolo (nc). Presença de parte de citoplasma do pneumócito tipo I $(*)$ e a membrana basal. Barras $=100 \mu \mathrm{m}$ 
durante essa fase do desenvolvimento. As células não seriam capazes de atuar na filtração do ar inspirado, uma vez que nessa fase do desenvolvimento não apresentam cílios.

Nos fetos com cinco meses de gestação, os pulmões estavam na fase canalicular, com o septo conjuntivo formado por TC frouxo e vascularizado (Figura 1C). Na extremidade dos bronquíolos respiratórios, observaram-se alvéolos primitivos formados por epitélio cúbico. Em alguns locais foram notadas células pavimentosas ou pneumócitos tipo I (PI) e células globosas ou pneumócitos tipo II (PII). Os PII apresentaram núcleo com aspecto esférico contendo cromatina agrupada no centro, se distribuindo de maneira uniforme até a periferia em pequenas zonas próximas ao envoltório nuclear, tendo o nucléolo evidente. No citoplasma desses pneumócitos, retículos endoplasmáticos e vesículas de secreção contendo substância estrolúcida no seu interior foram encontrados. Foi observado que uma parte do citoplasma do PI recobria o PII. Separando as duas células, uma membrana basal comum foi encontrada (Figura 1D). Os capilares estavam em contato com o epitélio (Figuras 1C e 1D).

Nessa idade gestacional, foi verificada rápida diferenciação celular, a fim de tornar a luz bronquial mais ampla e desenvolver os alvéolos primitivos na extremidade. Essas características são marcantes para o surgimento de células alveolares (PII), futuras responsáveis pela síntese de proteínas. BURRI (1984) descreve que nessa fase os bronquíolos terminais originam os bronquíolos respiratórios, os quais dividem-se, formando os ductos alveolares e sacos alveolares em suas paredes.

Foram observadas capilares em íntimo contato com o epitélio, dado que está de acordo com os achados de BURRI (1984), ao relatar que o crescimento periférico das vias aéreas é acompanhado pelo aumento da capilarização, na qual os capilares, no início, formam uma rede solta no parênquima e em seguida estabelecem pontos de contato com o epitélio cuboidal.

Segundo os achados da microscopia eletrônica de transmissão, pode-se aferir que os PII teriam condições de começar a produzir proteína surfactante aos cinco meses do período gestacional.

Aos seis meses de gestação, os pulmões estavam na fase de saco terminal. Nesse período do desenvolvimento, a vascularização pulmonar estava mais intensa e já foi possível observar, na parede do alvéolo, a presença de PI, juntamente com os PII que se encontravam em menor quantidade (Figuras 1E e F).
Os pulmões de fetos bovinos com seis meses de gestação foram classificados como estando em fase de saco terminal, pois a vascularização se tornou mais intensa, sendo possível observá-la nas paredes PI e PII. Apesar de as características citadas já estarem presentes na fase canalicular, estes foram classificados em período de saco terminal devido aos resultados de análise protéica, os quais demonstram presença de proteína surfactante (SP-A), que indicaria o início de síntese de proteínas pelos pneumócitos tipo II. Tal processo responsável pela síntese de proteínas é evidenciado pela presença do retículo endoplasmático e vesículas de secreção encontradas no citoplasma dos PII.

Aos sete meses de gestação, os pulmões apresentaram-se na fase de saco terminal "avançado", em que os sacos alveolares e os ductos alveolares eram visíveis, as células epiteliais de revestimento estavam presentes e o PI estava mai delgado (aspecto mais pavimentoso). Os capilares alveolares estavam mais evidentes, mais próximos das células epiteliais, e os PII apresentavam-se mais globosos (Figuras 2A e 2B). Os achados deste estudo para essa idade gestacional assemelham-se com os de GOERKE (1998). No entanto, foi acrescentadas ainda a presença de macrófagos nos septos alveolares e a acidofilia citoplasmática nos PII.

Nessa fase também foi observado que os PII continham corpos lamelares e vesícula de secreção no citoplasma. MOORE \& PERSAUD (2004) e O'RAHILLY \& MULLER (2005) descrevem a participação do PII na síntese de fosfatidilcolina dissaturada, sendo esse produto encontrado nos corpos lamelares. O núcleo apresentava cromatina agrupada em pequenas áreas no centro e próximas ao envoltório nuclear, com nucléolo evidente (Figura 2B). Essas mesmas características foram neste estudo.

A proteína surfactante $\mathrm{SP}$ - A mostrou-se abundante no pulmão, com bandas entre 26 e $36 \mathrm{kDa}$. Esse perfil eletroforético é semelhante ao de um animal recém-nascido (Figura 2E). As bandas entre 26 e $36 \mathrm{kDa}$ foram confirmadas para $\mathrm{SP}-\mathrm{A}$ pelo anticorpo policlonal anti $-\mathrm{SP}$ - A suíno e humano que reconheceram $\mathrm{SP}-\mathrm{A}$ no modelo bovino pela técnica de Western Blot (SAKAUCHI, 2006). Esse experimento foi realizado por integrantes do grupo de pesquisa que executou este trabalho, os quais verificaram a presença de 2 bandas: $\mathrm{SP}-\mathrm{A} 1$ e SP - A2. Tais características indicam o aumento da síntese protéica, uma vez que o envoltório nuclear contém ribossomos e é contínuo com o retículo endoplasmático rugoso.

Esses resultados estão de acordo com os achados de O'RAHILLY \& MULLER (2005) para o modelo humano, os quais relatam que a produção de 

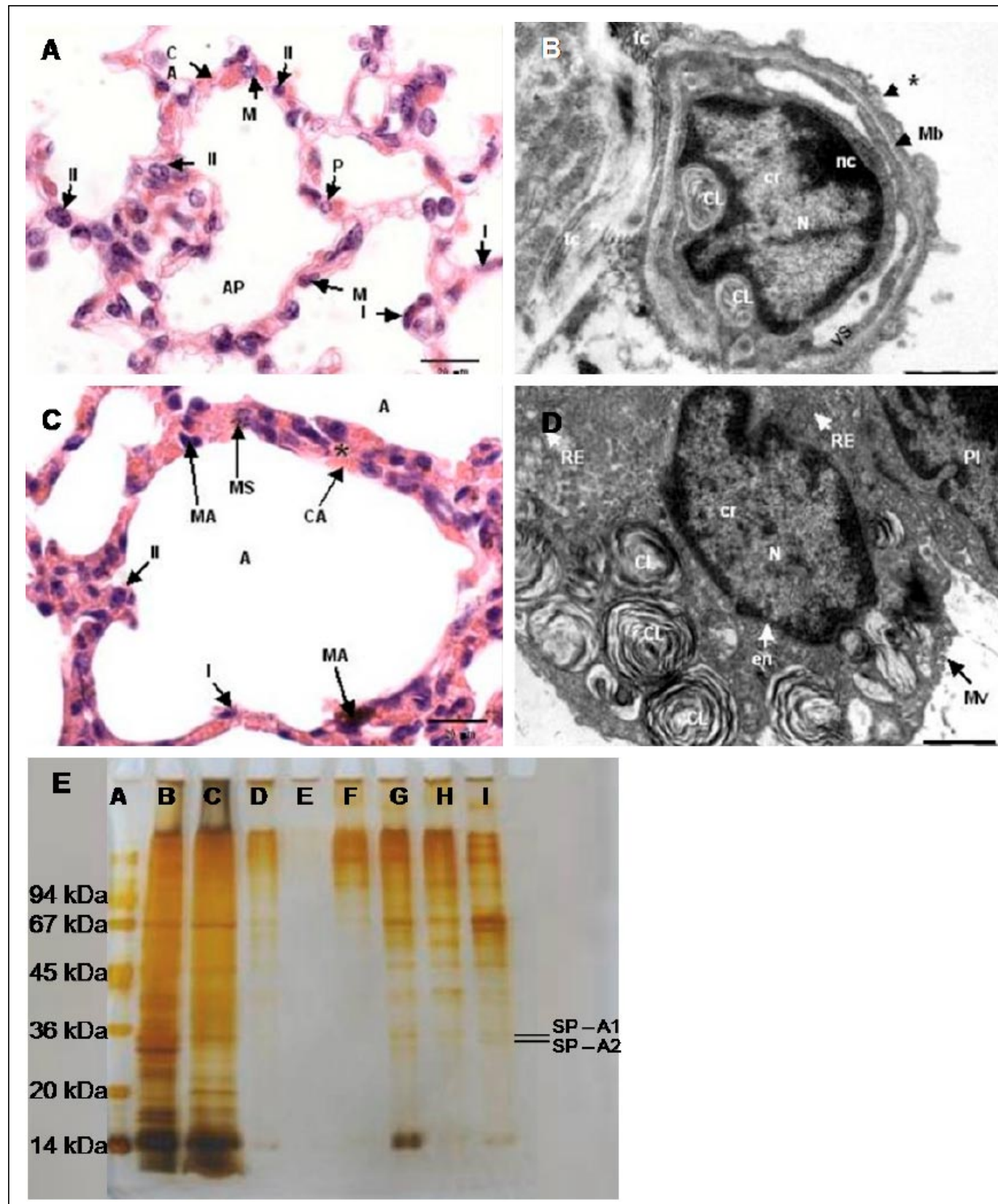

Figura 2 - Em A e B: Pulmão de feto bovino em fase de saco terminal com sete meses de gestação. Em A, microscopia de luz evidenciando: saco alveolar (SA), alvéolos primitivos (AP) contendo pneumócito tipo I (I) e pneumócito tipo II (II), capilares alveolar (CA), macrófago (M) e plasmócito (P). Em B: Eletromicrografia mostrando parede de um alvéolo primitivo. Notar: pneumócito tipo II com corpos lamelares (CL), vesícula de secreção (VS), membrana plasmática (Mp), núcleo (N) com cromatina (cr), envoltório nuclear (en), nucléolo (nc). Presença da membrana basal (Mb), de parte do citoplasma do pneumócito tipo I $(*)$, fibras colágenas (fc). Em C e D: cortes de pulmão de bovino recém nascido em fase alveolar. Notar em C: alvéolos (A), septo alveolar *, pneumócito tipo I (I), pneumócito tipo II (II), macrófago alveolar (MA) e macrófago no septo alveolar (MS), capilar alveolar (CA). Em D: Notar na eletromicrografia: pneumócito tipo II com corpos lamelares (CL) membrana plasmática com microvilosidades $(\mathrm{Mv})$, núcleo $(\mathrm{N})$ com cromatina (cr), envoltório nuclear (en), retículo endoplasmático (RE). Presença do núcleo de um pneumócito tipo I (PI). Em E: Perfis eletroforéticos de amostras de lavado bronco - alveolar em gel SDS - PAGE 12,5\% de marcador (ladder) (A), bovino adulto (B), recém nascido (C), e fetos com $5(\mathrm{D}, \mathrm{E}), 8(\mathrm{~F}), 7(\mathrm{G})$ e $6(\mathrm{H})$ meses de gestação respectivamente. As bandas $(\mathrm{SP}-\mathrm{A} 1$ e SP $-\mathrm{A} 2)$ de SP $-\mathrm{A}$ estão entre 26-36kDa. Barras $=100 \mu \mathrm{m}$ 
surfactante ocorre ainda na vida fetal. Acredita-se que o surfactante seja imunorregulador, mas sua principal função é a de reduzir a tensão superficial alveolar, facilitando os movimentos respiratórios. É importante ressaltar que a maturação pulmonar fetal está na dependência da adaptação pulmonar em se transformar de órgão secretor em um órgão de trocas gasosas e produtor de surfactante. BURRI (1984) concluiu que com o desenvolvimento e a maturação do sistema de surfactante durante o estágio sacular as chances de sobrevivência de um feto prematuro são maiores.

A quarta e última fase é o período alveolar que ocorre ao final do período fetal, quando os pulmões são capazes de realizar as trocas gasosas de forma eficiente(MOORE \& PERSAUD, 2004; SADLER, 2005). Nos fetos recém-nascidos, o pulmão encontrava-se na fase alveolar, com alvéolos definidos e parede alveolar contendo PI característicos (células pavimentosas), em contato com os capilares alveolares. Os PII também eram característicos, com formato globoso. Em alguns macrófagos alveolares presentes no septo alveolar, foi observada a presença de material fagocitado no seu interior (Figuras 2C e 2D).

Na membrana plasmática dos PII, foram observadas microvilosidades. Sugere-se que provavelmente elas são bicamadas lipídicas formadas por fosfolipídios contendo quantidade variável de moléculas protéicas, sendo mais numerosas nas membranas com maior atividade funcional, como referido por WARR (1987) e HAWGOOD \& SHIFFER (1991), o que há necessidade de renovação contínua da camada surfactante, uma vez que o órgão está em atividade constante. O núcleo possuía cromatina uniformemente distribuída no centro e agrupada na periferia em pequenas zonas próximas ao envoltório nuclear. Tais evidências indicam provavelmente o aumento da atividade na síntese de proteína surfactante no PII após o nascimento, que pode ser explicado pela necessidade de tal proteína para auxiliar o movimento respiratório que não existia antes do nascimento.

Os resultados da eletroforese SDS - PAGE e do lavado pulmonar dos recém-nascidos apresentaram o mesmo perfil eletroforético de um animal adulto, possuindo as mesmas "bandas", o que demonstra a presença das proteínas surfactantes (Figura 2E).

\section{CONCLUSÃO}

No 4ํ mês do período gestacional, os pulmões de fetos bovinos não apresentam pneumócitos do tipo I e II. Estes passam a ser observados entre o 5응 e o $6^{\circ}$ mês, ocorrendo também nesse período um aumento da vascularização. Com sete meses, os fetos possuem o pulmão em estágio de saco terminal avançado, contendo macrófagos e corpos lamelares produtores de proteína surfactante nos pneumócitos tipo II. Os dados sugerem, do ponto de vista da fisiologia respiratória, que nessa fase os pulmões dos fetos possuem as características necessárias para a síntese de proteínas surfactantes, possibilitando dessa forma uma possível funcionalidade do sistema respiratório do feto. Sendo assim, seria possível a sobrevivência viável do feto com sete meses, pois o pulmão apresenta características semelhantes àquelas observadas em animais nascidos a termo.

\section{COMITÊ DE ÉTICA E BIOSSEGURANÇA}

Este Projeto de Pesquisa foi aprovado pela Comissão de Bioética da Faculdade de Medicina Veterinária e Zootecnia da Universidade de São Paulo.

\section{REFERÊNCIAS}

ASSIS NETO, A.C. et al. Morpho-physical Recording of Bovine Conceptus (Bos indicus) and Placenta from Days 20 to 70 of Pregnancy. Reproduction in Domestic Animals, in press, 2009. Disponível em: <http://dx.doi.org/10.1111/j.14390531.2009.01345.x>. Acesso em: 05 Ago. 2009. doi: 10.1111/ j.1439-0531.2009.01345.x.

BLUM, H. et al. Improved silver staining of plant proteins rna and dna in polyacrylamide gel electrophoresis. Electrophoresis, v.8. p.93-99, 1987.

BURRI, P.H. Fetal and postnatal development of the lung. Annual Reviews Physiology, v.46. p.617-629, 1984.

CARDOSO, W.V. Transcription factors and pattern formation in the developing lung. American Journal of Physiology, v.269. p.429-442, 1995.

DYCE, K.M. et al. Tratado de anatomia veterinária. 3.ed. Rio de Janeiro: Elsevier, 2004. 813p.

EVANS, H.E.; SACK, W.O. Prenatal developmental of domestic and laboratory mammals: growth curves, external features and selected references. Anatomia Histologia Embryologia, v.2, p.11-45, 1973.

GOERKE, J.; CLEMENTS, J.A. Alveolar surface tension and lung surfactant. In: ROBERTSON, B.; TAEUSCH, H.W. (Eds.). Handbook of physiology. The Respiratoty System. Mecanism of Breathing. Bethesda: American Physiology Society, 1986. V.3, section 3, part I, p.247-261.

GOERKE, J. Pulmonary surfactant: functions and molecular composition. Biochimica and Biophysica Acta, v.1408, p.79-89, 1998.

HAFEZ, E.S.E.; HAFEZ, B. Reprodução animal. 7.ed. São Paulo: Manole. 2004. 513p.

WARR, R.G. et al. Nucleotide and amino acid of pulmonary surfactant protein SP 18 and evidence for cooperation between 
SP 18 and SP 28-36 in surfactant lipid adsorption. Proceedings of the National Academy of Science USA, v.84, p.66-70, 1987.

HAWGOOD, S.E.; SHIFFER, K. Structures and properties of the surfactant - associated proteins. Annual Review of Physiology. v.53, p.375-394, 1991.

JUNQUEIRA, L.C.; CARNEIRO, J. Histologia básica. 10.ed. Rio de Janeiro: Guanabara Koogan, 2004. 388p.

KOGISHI, K. et al. Isolation and partial characterization of human low molecular weight protein associated with pulmonary surfactant. American Review Respiratory Disease, v.137, p.1426-1437, 1988.

MOORE, K.L.; PERSAUD, T.V.N. Embriologia clínica. 7.ed Rio de Janeiro: Elsevier, 2004. 609p.

NODEN, D.M.; DE LAHUNTA, A. Embriologia de los animales domésticos. Zaragoza: Acribia, 1990. 399p.
O'RAHILly, R.; MULLER, F. Embriologia \& teratologia humanas. 3.ed. Rio de Janeiro: Guanabara Koogan, 2005. 468p.

PETERS, K. et al. Targeted expression of a dominant negative FGF receptor blocks branching morphogenesis and epithelial differentiation of the mouse lung. Embryo Journal,v.13, p.3296-3301, 1994

RIBEIRO, A.A.C. et al. A ramificação e distribuição do tronco pulmonar em relação aos brônquios, em fetos bovinos azebuados. Brazilian Journal of Veterinary Research and Animal Science, v.35, p.57-60, 1998.

SADLER, T.W. Langman - Embriologia médica. 9.ed. Rio de Janeiro: Guanabara Koogan, 2005. 347p.

SAKAUCHI, D. et al. Promissory source of porcine SP-A for multiple purposes. In: REUNIÃO ANUAL DA SBBq, 35., 2006 Águas de Lindóia, SP. Anais... Águas de Lindóia: Sociedade Brasileira de Bioquímica. 2006. Acessado em 22 maio 2009. On line. Disponível em: <http://sbbq.iq.usp.br/arquivos/2006/ cdlivro/resumos/R8578.html> 